\title{
THE DESIGN OF NEW HEALTHCARE BUSINESS MODEL: AN INTERDISCIPLINARY APPROACH
}

Renato Basso Nabuco (nabuco.renato@ufabc.edu.br) - Programa de Pós-Graduação em Engenharia e Gestão da Inovação, Universidade Federal do ABC

Anderson Orzari Ribeiro (anderson.ribeiro@ufabc.edu.br) - Programa de Pós-Graduação em Engenharia e Gestão da Inovação, Universidade Federal do ABC

Luciana Pereira (luciana.pereira@ufabc.edu.br) - Programa de Pós-Graduação em Engenharia e Gestão da Inovação, Universidade Federal do ABC

\begin{abstract}
Should not health insurance "ensure" health? Should not it promote health rather than calculate the price of the disease? Health Promotion is a process and encompasses the physical, mental and social well-being. Besides, demands a multidisciplinary approach to its development. Big companies have understand that promoting workers health, through workplaced wellness programs, is the right path to have healthier people been more productive, and there is a positive return of investment instead. However, small business, that employs more than a half of the work-force, do not have the power to play the game of Health Insurers and also do not have established health promotion programs for their members. So what should be the design of a new health insurance business model, centered in small businesses employees, that simultaneously promotes health and be economically viable? To answer this question, this paper analyses a collection of articles about health promotion programs, social ecological models of health promotion, service design and uses the triangulation to evaluate and examine how the three field of knowledge could contribute to the process. As a result, the authors present a new business concept for health care, designed for small businesses employees. The preliminary conclusions are that health promotion needs a multimethod and interdisciplinary approach, and the combining of education, environmental improvement, behavioral changing and technology are the players of a new business model concept. This paper is organized as follows. Section 2 describes the theoretical foundation that drives the research. Section 3 introduces the theory triangulation used. Sections 4 then combines the results from the individual sections to present the new concept. Finally, Section 5 presents our conclusions.
\end{abstract}

Keywords: health promotion, service design, business model, innovation

Field: The design and development of products and services 


\section{INTRODUCTION}

The healthcare sector comprehends the diagnosis, treatment, and prevention of disease, illness, injury, and other physical and mental injuries (LARRY CHAPMAN, 2003). Based on public policy and technological progress over recent decades, we have seen the improvement in the access to medical services, the evolution of diagnostic medicine equipment and less invasive therapeutic methods (HENKE et al, 2011).

As a result, life expectancy has been improving globally at a rate of more than 3 years per decade since 1950. For instance, the words average has up from 48 to 71.4 years. Meanwhile, between 1940 and 2015, the life expectancy in Brazil has increased from 45.5 to 75.5 years (World Health Statistics, 2016). In 2030, we will live up to 79.5 years. Whereupon, the demand is to ensure that the economically active population could aging well.

In order to achieve that, an emphasis on health promotion is necessary. According to the First International Conference on Health Promotion (Ottawa Charter, 1986), Health Promotion is the process of empowering the community to work on improving their quality of life and health. In addition, it assumes that each individual are in charge of his or her own process to reach a state of complete physical, mental and social well-being.

Conforming to O'Donnell (2009), Health Promotion is the art of science in helping people discover the synergies between their fundamental passions and optimal health. It is increased by self-motivation and changing of lifestyle toward an ideal state of health. For the author, the ideal health is a dynamic balance of physical, emotional, social, spiritual and intellectual health.

In Brazil, the National Agency for Supplementary Health (ANS), through Normative Resolution No. 264, of August 19, 2011, defines Health Promotion and Prevention and Control of Risks and Diseases as the political process that articulates sanitary, social, environmental and economic policies aimed at reducing vulnerability and health risks to the population; Empowerment of individuals and communities to change health determinants for the benefit of one's quality of life; And social participation in health policy management.

According to Baicker (2010), big companies have more resources and economies of scale necessary to implement and accomplish broad savings through employee wellness programs. Moreover, those enterprises are more likely than small employers to offer insurance. Only 48 percent of firms with 3 to 9 workers and 71 percent of firms with 10 to 24 workers offered health insurance, compared to 99 percent of firms with 200 worker or more (KAISER FAMILY FOUNDATION, 2011).

In fact, the business model of health insurance today is unfair for small business. The insurers charge a high premium even for healthy small groups because this group could became a high-risk if one or two members suffer a serious illness or injury (TIMOTHY S. JOST, 2012).

One way to encourage health promotion has been the workplace-based wellness programs. In this case, employer might benefit from investments in employee wellness. In other words, the health promotion programs could lead to reductions in health care costs. Meanwhile, healthier workers might be more productive (BAICKER et al, 2010).

The Small Business Administration (SBA) defines a Small Business as an enterprise with 500 or less employees. In the United States, over $50 \%$ of the workforce (120 million people) work in small business. In Brazil, 99.2\% of the markets are small business and they have been employ $52.3 \%$ of the work population, according to SEBRAE (2015). 
Given this scenario, our assumption is that the today's health insurance business models do not address the health promotion approach. Instead, the traditional systems have designed to treat the disease not to prevent it. What would then be a business model to promote health? What should be the design of this business model centered in members of small business that simultaneously promotes health and be economically viable?

To answer this question, this paper analyses a collection of articles about health promotion programs, and investigates how the social ecological models of health promotion and service design could contribute to the process. The hypothesis is that an innovative business model based on health promotion and health protection, focused on small businesses employees, would be the ideal place to disseminate the principles proposed by the Ottawa Charter.

As a result, the authors present a new business concept for health care, designed for small businesses laborers. The preliminary conclusions are that health promotion needs a multimethod and interdisciplinary approach, and the combining of education, environmental improvement, behavioral changing, organizational and regulatory interventions at several levels and technology are the players of a new business model concept.

This paper is organized as follows. Section 2 describes the theoretical foundation that drives the research. Section 3 introduces the methodology used throughout this paper. Sections 4 then combines the results from the individual sections to present the new concept. Finally, Section 5 presents our conclusions, limitations and future research.

\section{INNOVATION IN HEALTH PROMOTION PROGRAMS}

\subsection{Health Promotion in large companies}

Much discussion has taken place about investment in health promotion as a way of achieving better health outcomes at lowers costs. The workplace-based wellness programs, that affect directly prevention, have been showcased in the Barack Obama's reform of health sector proposal and also in the popular press and congressional hearings (STEINBROOK, 2009).

To Baicker et al. (2010), employer might benefit from investments in employee wellness: those health promotion programs could lead to reductions in health care costs, and healthier workers might be more productive. Furthermore, more than 60 percent of American get their health insurance coverage through an employment-based plan, as a "recognition" for the time that employees spend in the workplace.

The health promotion programs could also decrease the rates of absenteeism in companies. Aldana et al. (2004) have found that there is a significant difference in absenteeism among those who participate in voluntary wellness programs as opposed to those who not. The decrease in absenteeism translated into a cost saving of $\$ 15.60$ for every dollar spent on the program.

Chapman L. (2003) published his first study using a formal meta-evaluation of economic studies of worksite health promotion programs, with 42 studies that had met the study inclusion criteria. The original report was updated in 2005 and 2012, and now there are a total of 62 studies. Chapman selected only the articles classified as "program evaluations" by Medline and all selected studies must has meet all of the following criteria: (1) multicomponent programming: articles that include any combination of a minimum of three of the following types of programs: smoking prevention and cessation, physical fitness, nutrition, stress management, medical self care, high blood pressure control, cholesterol reduction, cardiovascular disease prevention, prenatal care, seat belt use, back injury prevention, back 
pain prevention, weight management, and nutrition education; (2) workplace setting only: programs conducted only in workplace setting for working populations; (3) reasonably rigorous study Design: use of a comparison or control group; (4) original research: articles must represent the initial or original publication; (5) examination of economic variable: Includes any one or a combination of health benefit plan costs, health care utilization indicators, sick leave absenteeism, workers' compensation costs, disability management costs, pension effects, or presenteeism effects; (6) publication in a peer-reviewed journal; (7) use a statistical analysis; (8) sufficient sample size; (9) replicable interventions; (10) minimum length of intervention period: articles must include an experimental or intervention period that is a minimum of 12 months in duration.

The search process used to identify the relevant literature was: online search of the business literature database, online search of Health and Social Sciences Database, review of selected publications for Program Evaluations Findings, back search of references from primary articles, and colleague inquiry.

To Chapman, in spite of the use of different approaches to the determination of economic impact, the summary highlights with average reductions in sick leave, health plan costs, and worker's compensation and disability insurance costs of around $25 \%$. For the author, worksite health promotion represents one of the most effective strategies for reducing medical cost and absenteeism.

In his study, Ozminkowski et al. (2006) have researched the experience of Medicare-covered retirees from a large manufacturing company who, along with their aged dependents, were offered a wide range of health promotion programs over an average of approximately six years, in a total of 59.324 participants. The health promotion programs included: (1) a health risk appraisal survey (HRA); (2) on-site biometric screenings; (3) telephone -based lifestyle management counseling (offered to high-risk individuals who measured biometric values for height, body weight, cholesterol levels, blood pressure and blood glucose); (4) self-care advice by nurse telephone line support service; and (5) educational classes offered at the worksite, to prevent those at low risk from becoming high-risk and helping those at high-risk improve their risk profile.

To evaluate the impact of health promotion program participation, they used the Growth Curve Analyses, an econometric statistical analyses to estimate the financial savings and compare trends in medical expenditures over time for five groups of Medicare beneficiaries, including those who: (1) never participated in any health promotion programs; (2) used only the HRA program but no other programs; (3) used the HRA program plus only one additional program; (4) used the HRA program plus two or more programs; and (5) did not used the HRA program but did use one or more program.

Mostly of members (53\% to 57\%)were female, ranged from 41 to 73 years. After the analyses, they have showed that using only the HRA program yielded an annual saving of $\$ 408$, and this number increases as the members added the participation in other programs together. The annual average savings for the Medicare programs ranged from $\$ 408$ (for HRAonly sample) to $\$ 569$ (for those who participated in HRA and two or more program). In this scenario of using the HRA survey in the health promotion program, the author suggests an annual savings ranging from $\$ 101$ to $\$ 646$ per person per year.

The existing research is more than adequate to provide business decision makers the evidence they need to understand how investment in workplace health promotion could save money. 


\subsection{Health Promotion in Small Business}

Goetzel and Ozminkowski (2008) in their study have raised evidences that suggest smaller firms are less likely to have successfully health promotion interventions compared to the larger workplaces that have the benefits of economies of scale and additional resources. Their research indicates that the implementation of worksite health promotion programs decreases at the size of the workplace decreases. They cited the most barrier for smaller business: lack of interest from workers, lack of knowledge, program costs, lack of resources and support from management.

McCoy et al. (2014) have conducted a systematic review to determine the quality of evidence of the published literature regarding about the barriers to adoption of worksite wellness programs in small business and about the effectiveness of those program in the improvement of small business worker's health. The search happened using databases PubMed and Web of Science, including articles up to an including September 2013. The criteria for study inclusion was: (1) English language, (2) business with less than 500 employees, (3) a descriptive or analytic assessment of a wellness program, (4) studies conducted in the United States. Nineteen of eighty-four articles fulfilled the criteria. They used the 2002 GRADEprofiler (GRADEpro) rating scale adapted by the World Health Organization to score each study. Only two studies met criteria for high rigor: Linnan et al. (2010) and Sorensen et al. (2005). MacCoy et al. concluded that they were unable to identify any studies that specifically address the hypothesis that large business solutions are generalizable to small business. They made a recommendation to be cautions and to no simply transfer large companies health promotion programs to small business, once there is not enough published evidence about the success of that. It is important to considering the many unique challenges faced by small worksites.

Smaller workplaces have some advantages in implementing workplace health promotion: (1) they have not a big distance between CEO and workers in lower hierarchical layers and this fact can facilitate the communication of the programs (LINNAN, 2010); (2) the intimate culture can help in promoting participation of all workers of the organization (Hunt et al, 2007); (3) the senior leaders can be more accessible and become an ambassador of the program (GOETZEL and OZMINKOWSKI, 2008).

Nonetheless, there is a principal problem that all companies, big or small ones, faced when we are discussing about health program: is how to motivate people to exercise, take care of their health and create a more healthy lifestyle to work better, live better and get old better?

\subsection{Social Ecological Models and Health Promotion}

Social ecology is views as an overarching framework, or set of theoretical principles, for understanding the interrelations among diverse personal and environmental factors in human health and illness. The perspective on health promotion is based, not on a singular discipline or theory, but rather on a broad, overarching paradigm that bridges several different fields of research (DANIEL STOKOLS, 1996).

Accordingly with the Social Ecological Theory, the health-promote capacity of an environment is understood, not simply in terms of the health effects on separate environmental features (air quality or social climate), but more broadly as the cumulative impact of multiple environmental conditions on occupant's physical, emotional, and social well-being, over a specified time interval (DANIEL STOKOLS, 1992).

The core theme of social ecological research is about environmental circumstances (multiple physical, social and cultural dimensions that can influence health outcomes); personal 
attributes (genetic heritage, psychological dispositions and behavioral patterns); and also domains of human activity (zip code of residence, neighborhood, zip code of workplace) (WALLERSTEIN, 1992).

Thus, efforts to promote human health must take into account the interdependencies that exist among immediate and more distant environments, like the rout between workplace to residential environment (CAL/OSHA, 1995 and ASHFORD, 1988).

\subsection{Healthcare Innovation and Service Design}

Over the past decade, a profession of service designer has emerged and an interdisciplinary field of service design research has begun to take shape. One of the core issues for this field is to put users in the center for the design of a solution. To be able to this, the service designer uses various empathic research methods (SEGELSTRÖM et al, 2009).

There is relatively little literature analyzing the work of professional service designers. Although the field of service design is small and fragmented, without strong professional bodies or a developed research literature, it is visible through conferences within universities, a professional Service Design Network with annual conferences, books, and through the work its practitioners publish in reports and on websites (KIMBELL, 2011).

The Health Care area is a completely different environment that requires a multi-interdisciplinary vision. It is a complex system that address to several stakeholders and need to be a "patient-centric". In this scenario, we need an approach that understands the multiplicity of interactions and service design can help to understand the human needs (FREIRE, 2010).

There is two different approaches to innovation on the healthcare area that service design have been used: working within organizations to create new service configurations; or acting outside the system to generate disruptive innovation. The strategy is to move toward a codesign and co-production to co-creation philosophy.

Co-design in healthcare services implies a partnership between patients, professionals and community working together in the design development process (SANDERS and STAPPERS, 2008). The co-production uses people's capacities to deliver public services in an equal and reciprocal relationship, shifting the balance of power, responsibility and resources from professionals to individuals (BOYLE and HARRIS, 2009). Finally, cocreation happens when users are central not only to the design of services, but also to their production and continuous development. It is based on people generating the content of service and shaping their nature (MURRAY et.al, 2006).

\section{RESEARCH DESIGN}

\subsection{Data Collection}

We collected the most cited articles of the three field related: health promotion programs, social ecological models of health promotion, and service design. We used the Web search platforms PubMed, Google Scholar and Scopus.

Our initial search was undertaken using the basic keywords such as: health promotion programs and we made three different associations: with return of investment, social ecological and service design. Only articles and review were selected. The keywords were used as a selection criterion for the topic (title, keywords or abstract) and classified for the 'cited by (highest)', resulting in an initial sample of 43 papers. None article was found using the association health promotion program and service design. Therefore, another criteria were 
used, associating the words healthcare innovation and service design to find 09 new articles that were selected for the purpose of this work.

\subsection{Data Analysis and Validation}

The survey of articles pertaining to the three fields of study (health promotion programs, social health models of health promotion and service design) resulted in 52 articles.

However, it was necessary to carefully carry out the selection of the pertinent information to understand the different points of view around the health promotion and health promotion programs. Thus, the following questions were asked about the selected articles of each combination:

Table 1. Validation questions

\begin{tabular}{|l|l|}
\hline Combination & Question \\
\hline $\begin{array}{l}\text { "Health promotion program" and "return of } \\
\text { investment" }\end{array}$ & $\begin{array}{l}\text { How a program of health promotion needs to } \\
\text { be built to generate positive return of } \\
\text { investment? }\end{array}$ \\
\hline $\begin{array}{l}\text { "Health promotion program" and "social } \\
\text { ecological" }\end{array}$ & $\begin{array}{l}\text { How should be the guidelines for the design } \\
\text { and evaluate of health promotion programs? }\end{array}$ \\
\hline "Healthcare Innovation" and "service design" & $\begin{array}{l}\text { How the service design methodology could } \\
\text { help us to understand the real human needs } \\
\text { for health promotion and innovation? }\end{array}$ \\
\hline
\end{tabular}

In order to validate our findings, we used perspective triangulation. Triangulation uses different theoretical perspectives to look at the same data. The core is to understand how findings are affected by different assumptions and fundamental premises. The examination of some data through opposite perspectives represents different theories of action that can shine others paths (PATTON, 1999).

The logic behind is based on the premise that no single method ever adequately solves the problem of rival explanations. Thus, multiple sources analysis providing more accurate results (DENZIN, 1978).

\section{THE DESIGN OF A NEW CONCEPT}

Analyzing the literature about the return of investments about health promotion programs in large companies, the existing research is more than adequate to provide business decision makers the evidence they need to understand how investment in workplace health promotion could save money. But there are still missing one answer to be respond: How to design health promotion programs to small employers, and how apply all information we have about return of investments of health programs in the startup world?

In other hand, during the analysis of health programs in small business, we could conclude that: (1) smaller workplaces (with less than 1,000 employees) constitute the vast majority of US workplaces and employ half of working US adults;(2) the employees of smaller workplaces are more likely than employees of larger workplaces to be low-wage earners and are at increased risk for chronic diseases; (3) smaller workplaces are less likely than larger workplaces to offer workplace health promotion programs; (5) smaller workplaces are also unlikely to offer health insurance; (6) some health-promotion interventions in smaller 
workplaces have been effective in changing behavior, but more research is needed.

But the focus of literature is on large or small business. And to create a new concept of a business that are intended to promote health, we need to consider the employees. We need to be more human-to-human ( $\mathrm{H} 2 \mathrm{H}$ instead of B2B or B2C) and assume this vision to create empathy, one pillar of the service design.

The design of a new concept of business model in health care necessarily needs to consider the ZIP code of the individual: the place where he lives, the place of work and all the path that interconnects these two locations.

Figure 1. Basis of the New Concept. Source: from the Author

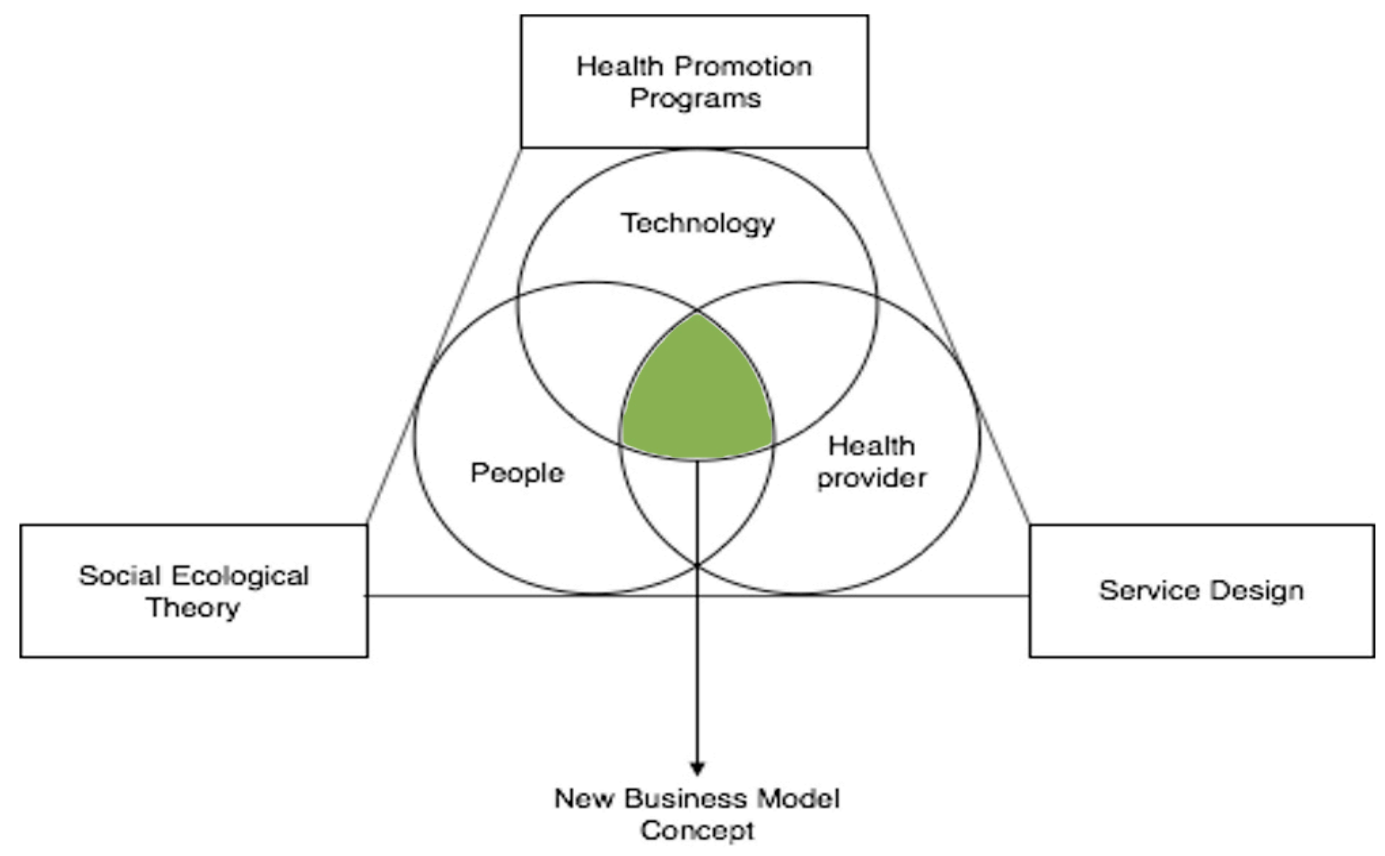

Through the service design approach we can generate this necessary empathy to understand the real needs of each individual. With the methodology, we designed the entire journey of the person and we were able to identify the main limiting factors as well as the opportunities to implement true health promotion. Through service design, we can see all the social Ecological theory happen.

Technology is considered a fundamental point of the new concept. Through app solutions we will be able to map and reach our end client, as well as connect health service providers directly with their right consumers (Figure 1.0).

The behavioral changing is a "baby steps" process, in the same way as health promotion. It is a day-by-day process and we need to understand the motivation and the abilities of our user. In this way, we will be able to create the correct trigger, in the perfect moment, to promote the biggest changes.

Finally, the design of a new health insurance business model centered in small businesses employees, which simultaneously promotes health and is economically viable needs to use the artificial intelligence and combine it with medical knowledge. And the solution needs to be more customization; the more the final user interacts with the technology. 


\section{CONCLUSIONS}

Ecological analyses of health promotion encompass a broad range of theoretical and disciplinary perspective. The resulted knowledge needs to be associated with all the insights that service design brings to light, and all of it combined with technology. This paper presents a combination of different areas of knowledge associated with a common view of health promotion. Through theory triangulation, different points of view create a new concept on the subject.

This article presents a limitation for have only literature data. An exploratory research through service design is needed to collect qualitative data (and insights) around the needs of small business employees.

\section{REFERENCES}

.Agência Nacional de Saúde Suplementar (Brasil). Resolução Normativa n. 264, de 19 de agosto de 2011 da Diretoria de Normas e Habilitações de Produtos - DIPRO.

ALDANA, S.G.; MERRILL, R.M.; PRICE, K., et al. Financial impact of a comprehensive multisite workplace health promotion program. Prev Med. 2005;40:131-137.

ASHFORD, N.A. Federal regulation of occupational health and safety in the workplace. Occupational health: recognizing and preventing work-related disease, 2nd edition. Boston: Little, Brown 1988;135-48.

BAICKER,K.; CUTLER,D.; SONG,Z. Workplace wellness programs can generate savings. Health Aff.2010;9:1-8.

BAUM, A.; GATCHEL, R.J.; SCHAEFFER, M.A. Emotional, behavioral, and physiological effects of chronic stress at Three Mile Island. J Consult Clin Psychol 1983;51:565-72.

BOYLE, D.; HARRIS, M. The Challenge of Co-Production. 2009 London: NESTA.

CAL/OSHA. Model injury and illness prevention program for workplace security.

Sacramento, California: State of California, Department of Industrial Relations, Division of Occupational Safety Health, 1995.

CHAPMAN, L. Meta-evaluation of worksite health promotion economic return studies. Am J Health Promot. 2003;17(3):1-10.

CHAPMAN, L. Meta-evaluation of worksite health promotion economic return studies: 2005 Update. Am J Health Promot. 2005;19(6):1-10.

DENZIN, N.K. Sociological Methods. New York: McGraw-Hill, 1978.

DENZIN, N. K. Triangulation 2.0. Journal of Mixed Methods Research, v. 6, n. 2, p. 80-88, 201.

FREIRE, K.; SANGIORGI, D. Service design and Healthcare innovation: from consumption, to co-production to co-creation, Nordic Service Design Conference, Linkoping, Sweden, 2010.

HENDERSON, D.A.; SCUTCHFIELD, F.D. Point-counterpoint: the public health versus medical model of prevention. Am J Prevent Med 1989;5:113-9. 
HENKE, R.M.; GOETZEL, R.Z.; MCHUGH, J.; ISAAC, F. Recent experience in health promotion at Johnson \& Johnson: lower health spending, strong return on investment. Health Aff (Millwood). 2011;30:490 499.

GOETZEL,R.Z.; OZMINKOWSKI,R.J. The health and cost benefits of worksite healthpromotion programs. Annu. Rev. Public Health 2008,29:303-23

INTERNATION CONFERENCE ABOUT HEALTH, 1, 1986, Ottawa. Ottawa Charter. Ottawa, 1986.

KAISER FAMILY FOUNDATION, Health Research and Educational Trust. Employer health benefits: 2011 annual survey. Menlo Park (CA): KFF; 2011 Sep.

KAISER FAMILY FOUNDATION, Health Res. Educ. Trust, NORC Univ. Chicago. 2012. Employer Health Benefits - 2012 Annual Survey. Menlo Park, CA: Kaiser Family Found.

KIMBELL, LUCY. Designing for Service as One Way of Designing Services. International Journal of Design, suppl. Special Issue; Taipei5.2 (Aug 15, 2011)

KIMBELL, L.; SEIDEL, V., P. Designing for Services - Multidisciplinary Perspectives: Proceedings from the Exploratory Project on Designing for Services in Science and Technology-based Enterprises, Saïd Business School - 2008. Available at http://www.sbs.ox.ac.uk/D4S/essayArchive/index.html

McCOY, K.; STINSON, K.; SCOTT, K.; TENNEY, L.; NEWMAN, L. S. Health Promotion in Small Business: A Systematic Review of Factors Influencing Adoption and Effectiveness of Worksite Wellness Programs. Journal of Occupational and Environmental Medicine / American College of Occupational and Environmental Medicine, 2014;56(6), 579-587.

MURRAY, R.; BURNS, C.; VANSTONE, C.; WINHALL, J. RED, 2006, Report 01: Open Health. London: Design Council.

O’DONNELL, M.P: Definition of Health Promotion 2.0: Embracing Passion, Enhancing Motivation, Recognizing Dynamic Balance, and Creating Opportunities. American Journal of Health Promotion: September/October 2009, Vol. 24, No. 1, pp. iv-iv, updated from Michael P. O'Donnell (1986), Definition of Health Promotion, American Journal of Health Promotion, June 1986; vol. 1, 1: pp. 4-5.

OZMINKOWSKI, R.J.; GOETZEL, R.Z.; WANG, F., et al. The savings gained from participation in health promotion programs for Medicare beneficiaries. J Occup Environ Med. 2006;48:1125-1132.

PATTON, M.Q. Enhancing the quality and credibility of qualitative analysis. HSR: Health Services Research. 199934 (5) Part II. pp. 1189-1208.

SORENSEN, G.; BARBEAU, E.; STODDARD, A.M.; HUNT, M.K.; KAPHINGST, K., WALLACE, L. Promoting Behavior Change Among Working-Class, Multiethnic Workers: Results of the Healthy Directions - Small Business Study. American Journal of Public Health: August 2005, Vol. 95, No. 8, pp. 1389-1395.

SANDERS, E.; STAPPERS, P. J. Co-creation and the new landscapes of design. Co-design, 2008, p.1-16.

SEGELSTRÖM, F.; HOLMLID, S. Visualization as tools for research: Service designers on visualizations. InNorDes 2009-Engaging artifacts, Nordic Design Research Conference 2009 Aug 30. 
STOKOLS, D. Establishing and maintaining healthy environments: toward a social ecology of health promotion. American Psychologist.1992b;47:6-22.

STOKOLS, D. Translating social ecological theory into guidelines for community health promotion. Am J Health Promotion 1996;10:282-298.

TIMOTHY, S. J. Employers and the Exchanges under the small business health options program: examining the potential and the pitfalls. Health Affairs $31 n^{\circ} 2$ (2012):267-274.

WALLERSTEIN,N. Powerlessness, empowerment, and health: implications for health promotion programs. Am J Health Promot 1992;6:197-205.

WORLD HEALTH ORGANIZATION. Action plan for the global strategy for the prevention and control of noncommunicable diseases 2008-2013. Geneva, 2008. 